\title{
Obesity, Metabolic Syndrome, and Diabetes: Cardiovascular Implications and Therapy
}

\author{
Eduardo Alegría Ezquerra, José M. Castellano Vázquez, and Ana Alegría Barrero
}

Departamento de Cardiología, Clínica Universitaria de Navarra, Pamplona, Navarra, Spain

Obesity, metabolic syndrome, and type-2 diabetes mellitus are 3 interrelated conditions that share a number of pathophysiological mechanisms and that are frequently observed to lead, in succession, to cardiovascular complications. The fact that their prevalence is increasing alarmingly should prompt all healthcare professionals urgently to implement measures to prevent these complications. The most effective, though also the least adopted, are those related to lifestyle modification. Drug treatment targeted at controlling risk factors (eg, hypertension, dyslipidemia, and thrombophilia), metabolic abnormalities, and excess weight is also necessary.

Key words: Diabetes. Metabolic syndrome. Obesity.

\section{Obesidad, síndrome metabólico y diabetes: implicaciones cardiovasculares y actuación terapéutica}

Obesidad, síndrome metabólico y diabetes mellitus tipo 2 son tres enfermedades interrelacionadas que comparten mecanismos de aparición y evolución y con frecuencia se van combinando sucesivamente y ocasionan complicaciones cardiovasculares. Su prevalencia crece alarmantemente y debería impeler a los profesionales de la salud y a los gestores a implantar medidas urgentes para prevenir la aparición de complicaciones. Las más eficaces, aunque menos practicadas, son las relacionadas con el estilo de vida. También son necesarios tratamientos farmacológicos destinados al control de los factores de riesgo (hipertensión, dislipemias, trombofilia), las alteraciones metabólicas y el propio exceso de peso.

Palabras clave: Diabetes. Síndrome metabólico. Obesidad.

\section{INTRODUCTION}

Few will disagree that obesity is fast becoming the 21 st century's most serious health problem. It is a condition which begins in childhood, flourishes in adulthood, and leads to multiple health problems. Genetic and molecular factors, other exacerbating circumstances, and environmental and behavioral triggers all play a part in its development and determine its treatment. ${ }^{1}$ Type 2 diabetes mellitus (DM2) is a metabolic disease arising from flaws in the action of insulin in the peripheral tissues. The resulting chronic hyperglycemia is accompanied by damage to organs, particularly the eyes, kidneys, and heart, as well as to nerves and arteries.

\section{Section Sponsored by Laboratorio Dr Esteve}

Correspondence: Dr. E. Alegría.

Dpto. de Cardiología. Clínica Universitaria de Navarra.

Avda. Pío XII, s/n. 31008 Pamplona. Navarra. España.
The present article reviews the definitions and physiopathology of obesity and the related diseases of metabolic syndrome (MS) and DM2. It reviews the cardiovascular implications and complications of these diseases as well as preventive and therapeutic measures against these conditions and the accompanying cardiovascular risk.

\section{DEFINITIONS}

\section{Obesity}

Obesity is defined as an excess of corporal adiposity. For practical reasons, body weight has been used as an indirect measure of the degree of adiposity as the latter is not easy to measure with the usual tests. In the eighties, the concept of body mass index (BMI) was introduced and cut points were established to define overweight and obesity in adult men and women. ${ }^{2}$ Values were later established for children and adolescents (Table 1). ${ }^{3,4}$

Independent of the fact that high BMI values are associated with adverse risk profiles for morbidity and mortality, particularly in relation to DM2 and 

ABBREVIATIONS
BMI: body mass index
CVD: cardiovascular disease
DM2: type 2 diabetes mellitus
HBP: high blood pressure
HDL: high density lipoproteins
MS: metabolic syndrome

atherothrombotic cardiovascular disease (CVD), various sub-types of obesity have been described which complement the apparent dose-response relationship between BMI and its impact on health. The most classic sub-types are android obesity (abdominal) and gynoid obesity (gluteal obesity)., ${ }^{5,6}$ Less well-known sub-types are, however, also of interest. For example, a phenotype corresponding to metabolically obese normal-weight (MONW) individuals has been reported. These individuals have a normal BMI together with some of the characteristics of obese individuals such as insulin resistance, central adiposity, low levels of high density lipoproteins (HDL) and high levels of triglycerides, and high blood pressure (HBP). ${ }^{7}$ At the same time, metabolically healthy obese (MHO) individuals have also been identified. ${ }^{8}$ These individuals have $\mathrm{BMI}>30$, but none of the metabolic alterations which are typical of obese individuals.

The existence of these 2 "paradoxical" sub-types led to several studies over the last 2 decades which aimed to metabolically characterize and quantify visceral adipose tissue as opposed to subcutaneous adipose tissue. These studies showed that the quantity of visceral adipose tissue is directly correlated in both men and women with a seriously altered metabolic risk profile which precedes the development of DM2 and cardiovascular disease. Therefore, although it is true that obesity increases the risk of chronic disease, it seems clear that patients with visceral obesity form a sub-group of individuals with the most serious metabolic alterations. It has been demonstrated, for instance, that the regional accumulation of fatty tissue in the visceral deposits is a more reliable predictor of cardiovascular risk than the total quantity of body fat. The multi-country INTERHEART case-control study confirmed the importance of adiposity, and particularly abdominal adiposity, as a risk factor for acute myocardial infarction. ${ }^{9}$

\section{Metabolic Syndrome}

In recent years, MS has caused an authentic revolution in vascular risk stratification and has become one of the most widely used concepts within the health sciences. It describes the accumulation within an individual patient of several very prevalent conditions in western countries,
TABLE 1. Definitions of Obesity According to Body Mass Index 3,4

\begin{tabular}{lcc}
\hline Category & Children and Adolescents $^{\mathrm{a}}$ & Adults $^{\mathrm{b}}$ \\
\hline Underweight & $<\mathrm{p5}$ & $<18.5$ \\
Normal weight & $\mathrm{p5}-85$ & $18.5-24.9$ \\
Risk of overweight & $\mathrm{p} 85-90$ & - \\
Overweight & $>\mathrm{p} 95$ & $25-29.9$ \\
Grade 1 obesity & - & $30-34.9$ \\
Grade 1 obesity & - & $35-39.9$ \\
Morbid obesity & - & $40-49.9$ \\
Super-morbid obesity & - & $>50$
\end{tabular}

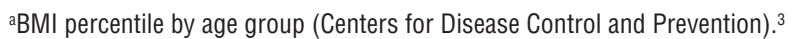
${ }^{\circ}$ Body mass index $(\mathrm{BMI})=$ weight $($ in $\mathrm{kg}$ )/height (in $\mathrm{m}$ ) squared ( $\mathrm{NIH}$ and $\mathrm{OMS}^{4} ; \mathrm{p}=$ percentile.

all of which are risk factors for CVD and DM2. The 2 underlying mechanisms of MS are abdominal adiposity and insulin resistance. ${ }^{10}$ it is exacerbated by age, genetic conditioning, and an inappropriate lifestyle which includes physical inactivity and the consumption of high calorie, high-fat foods, concentrated carbohydrates, and salt. These metabolic alterations occur simultaneously more frequently than would be expected by chance and the concurrence of several factors increases cardiovascular risk over and above the risk associated with the individual factors alone. ${ }^{11}$

There are numerous definitions of MS. Although all of the classifications include the syndrome's essential components, they differ on details or on whether to include components which are difficult to measure. The two most widely used definitions are those of the International Diabetes Federation ${ }^{12}$ classification and the definition included in the latest revision of the ATP-III (Adult Treatment Panel III of the United States' National Cholesterol Education Program). ${ }^{13}$ The 2 classifications are very similar and are summarized in Table 2.

The risk factors constituting MS are atherogenic dyslipidemia, high blood pressure, glucose metabolism disorders, and proinflammatory and prothrombotic states, ie all of the classic CVD risk factors except for smoking, family history, and age. Atherogenic dyslipidemia includes higher levels of apolipoprotein B containing lipoproteins and triglycerides, a greater number of small low density lipoprotein (LDL) particles (with a higher atherogenic cholesterol content), and low concentrations of HDL. Although they are not included in the definition of MS, other biological markers can sometimes be useful, such as those related to adipose tissue (percentage of abdominal fat using digital tomography, leptin/adiponectin ratio), other markers of dyslipidemia (apolipoprotein B or size of LDL particles), endothelial dysfunction (measured by the vasodilatory response in the humeral artery), inflammation markers (C-reactive protein) or thrombosis markers (high fibrinogen or plasminogen activator inhibitor-1 $)^{13}$ (Table 3). 


\section{TABLE 2. Diagnostic Criteria for Metabolic Syndrome}

International Diabetes Federation (2005) ${ }^{12}$

Central adiposity (waist circumference for European population:

males, $>94$; females, $>80 \mathrm{~cm}$ ) and 2 or more of:

Triglycerides $>150 \mathrm{mg} / \mathrm{dL}$ or specific treatment

$\mathrm{HDL}<40$ (males) or $<50 \mathrm{mg} / \mathrm{dL}$ (females) or treatment

Blood pressure $>130 / 85 \mathrm{~mm} \mathrm{Hg}$ or treatment for hypertension

Baseline blood glucose $>100 \mathrm{mg} / \mathrm{dL}$ or prior diagnosis of diabetes

National Cholesterol Education Program (ATP-III) (2002) ${ }^{13}$

Three or more of the following criteria:

Fasting glucose $>110 \mathrm{mg} / \mathrm{dL}$ [100]

Blood pressure $>130 / 85 \mathrm{~mm} \mathrm{Hg}$ [or treatment]

Triglycerides $>150 \mathrm{mg} / \mathrm{dL}$ [or treatment]

HDL cholesterol [or treatment]

$<40 \mathrm{mg} / \mathrm{dL}$ in males

$<50 \mathrm{mg} / \mathrm{dL}$ in females

Abdominal adiposity

Waist $>102 \mathrm{~cm}$ (males)

Waist $>88 \mathrm{~cm}$ (females)

HDL indicates high density lipoproteins.

The details in square brackets were added in 2005 to adapt to the IDF definition.

\section{Diabetes}

The American Diabetes Association diagnostic criteria for diabetes are clear ${ }^{14}: a$ ) casual plasma glucose level $>200 \mathrm{mg} / \mathrm{dL}$ in a patient with characteristic symptoms ("casual" is defined as an analysis performed at any time of day independently of the time of the last food intake), polyuria, polydipsia, and weight loss; or $b$ ) fasting glucose level $>126 \mathrm{mg} / \mathrm{dL}$ confirmed in 2 determinations (fasting is defined as the absence of caloric intake during at least $8 \mathrm{~h}$ ); or $c$ ) plasma glucose values $2 \mathrm{~h}$ after an oral glucose load $>200 \mathrm{mg} / \mathrm{dL}$; the test should be performed according to the WHO guidelines, using a standard drink containing the equivalent of $75 \mathrm{~g}$ of anhydrous glucose dissolved in water.

As well as diabetes, other pre-diabetic syndromes which are reflected in the concept of glucose metabolism disorders are diagnosed in patients who do not meet the criteria for a diagnosis of diabetes but who have higher than normal basal glucose levels or after loading. Figure 1 summarizes the criteria for the diagnosis of altered basal glucose values and glucose intolerance. ${ }^{14}$

\section{PHYSIOPATHOLOGICAL ASPECTS}

Details on the mechanisms underlying the type of vascular injuries which are produced by the 3 inter-related conditions under consideration, ie obesity, MS, and DM2 go beyond the scope of this review article. Few brief pointers are provided.

Obesity is a risk factor for atherosclerosis due to a variety of mechanisms which are summarized in Figure 2. Insulin resistance, which is the common link with MS,
TABLE 3. Other Components of Metabolic Syndrome

\begin{tabular}{ll}
\hline Criteria & Markers \\
\hline Adiposity & Visceral adiposity (TD) \\
& Nonalcoholic steatohepatitis \\
Adipose tissue markers & $\begin{array}{l}\text { Leptin, adiponectin } \\
\text { Dyslipidemia }\end{array}$ \\
& $\begin{array}{l}\text { Size of LDL particles } \\
\text { Direct estimation }\end{array}$ \\
Insulin resistance & Oral glucose tolerance test \\
Endothelial dysfunction & Humeral vasodilatory response \\
& Albuminuria \\
Inflammation or thrombosis & PCR, TNF $\alpha$, IL-6 \\
& PAI-1, fibrinogen \\
\hline
\end{tabular}

IL indicates interleukin; PAI, plasminogen activator inhibitor; CRP, C-reactive protein; CD, computerized tomography; TNF, tumor necrosis factor.

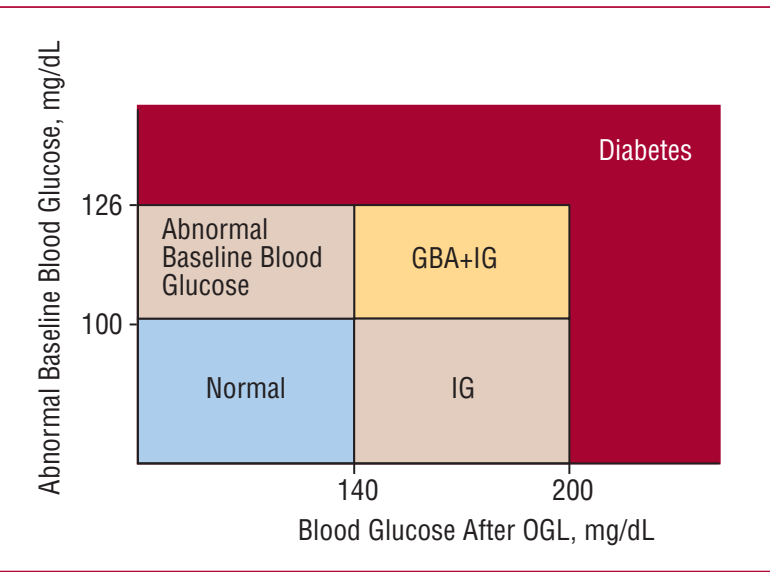

Figure 1. Concept of glucose metabolism disorder (American Diabetes Association criteria $\left.{ }^{14}\right)$. Diabetes is diagnosed when several determinations of basal glucose levels (after $12 \mathrm{~h}$ of fasting) exceed $126 \mathrm{mg} / \mathrm{dL}$ or if glucose levels $2 \mathrm{~h}$ after an oral load of $75 \mathrm{~g}$ of glucose (OGL) exceed 200 $\mathrm{mg} / \mathrm{dL}$. Glucose levels of 100 to $126 \mathrm{mg} / \mathrm{dL}$ indicate a diagnosis of "abnormal glucose levels" (AGL) and between 140 and $200 \mathrm{mg} / \mathrm{dL}$ after OGL indicate "glucose intolerance" (GI).

leads to glucose metabolism disorders, dyslipidemia, high blood pressure, endothelial dysfunction, and inflammation induced by cytokine imbalance. The latter, ie an excess of harmful cytokines (interleukins 6 and 18, tumor necrosis factor alpha, and leptin being among the most important) combined with a scarcity of protector cytokines (adiponectin). ${ }^{15}$

Central adiposity, one of the principal characteristics of MS, provides the foundation for the portal/visceral theory, which suggests that the increase in adiposity, particularly in visceral deposits, leads to an increase in the flow of free fatty acids and the inhibition of insulin action. The large quantity of non-sterified fatty acids reduces the use of glucose by skeletal muscle, stimulates the hepatic production of very low-density lipoproteins and glucose, and propitiates the acute secretion of insulin. 
Figure 2. Diagram of atherosclerosis pathogenesis in obesity. The three main mechanisms are insulin resistance, increased free fatty acids, and cytokine imbalance. FFA indicates free fatty acids; HDL-C, high density lipoprotein cholesterol; LDL-C, low density lipoprotein cholesterol; DM2, type 2 diabetes mellitus; HBP, high blood pressure; GI, glucose intolerance.

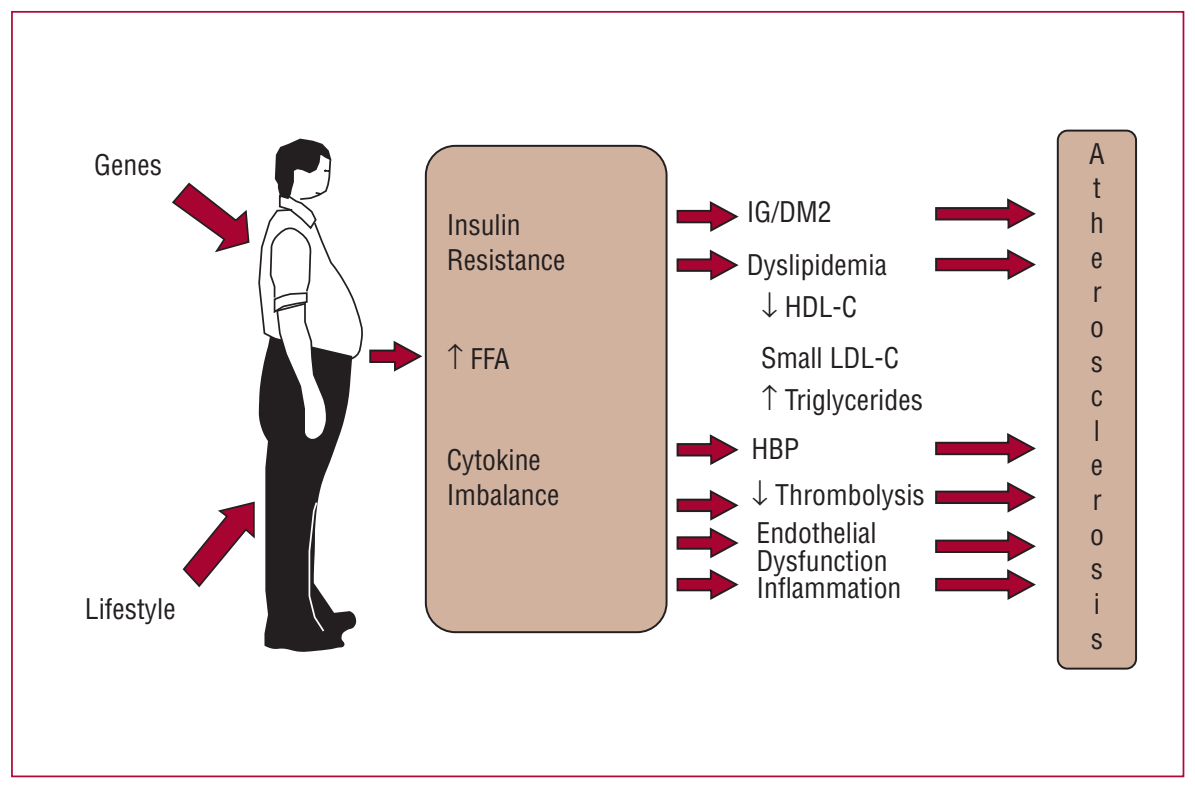

The lipotoxic effect in the pancreatic beta cells caused by free fatty acids over the long term could be part of the connection between obesity, insulin resistance, and the development of DM2. However, the portal theory has been placed in quarantine and there is some evidence that it is unable to explain, by itself, all of the metabolic anomalies present in abdominally obese individuals. ${ }^{16,17}$

There was considerable debate as to whether MS increases the risk of cardiovascular disease to a greater degree than the sum of its individual parts, though it has now clearly been shown that this is the case. In the first place, epidemiological studies have demonstrated that the degree of risk involved when multiple risk factors are present is greater than the sum of the risks attributable to each individual factor; in other words, under these circumstances, risk increases geometrically rather than linearly. In the second place, the algorithms habitually used to calculate cardiovascular risk do not include several metabolic factors which have been shown to independently increase the risk of vascular complications. These include the prothrombotic state, inflammatory status, and hypertriglyceridemia. The additional risk associated with these factors exceeds that attributed to conventional risk factors. In the third place, some of the risk attributed to conventional factors probably derives from factors which have not been considered or measured. Finally, as MS progresses and often culminates in DM2, the risks associated with the latter should be added to those already mentioned. The evolution of MS in terms of its pathological consequences are shown in Figure 3. ${ }^{16}$

Figure 4 summarizes the latest theories regarding the relationship between obesity and MS, which is posited as a dysfunction of adipose tissue with insulin resistance appearing later when compensatory response mechanisms have been exhausted. ${ }^{17}$
From what has been described here, it is clear that MS is a first order risk factor for atherothrombotic complications. Its presence or absence should therefore be considered an indicator of long-term risk. On the other hand, over the short term (5-10 years) risk is better calculated using the classical algorithms (Framingham, SCORE, REGICOR), as they include age and sex, total cholesterol or LDL, and smoking. ${ }^{16}$

The basic cardiovascular complications produced by hyperglycemia in DM2 are microangiopathic disease (diabetic nephropathy, retinopathy, and diabetic neuropathy) and CVD (diabetic macroangiopathy). These include coronary heart disease and stroke as the main complications, although peripheral arterial disease is also common and tends to be more serious (higher indices of serious ischemia and amputations) when it is cause by diabetes than when it is caused by other mechanisms. Cardiovascular diseases is the most important complications of DM2, both in clinical and numerical terms and represent up to $80 \%$ of the macrovascular complication attributed to the disease. ${ }^{18,19}$ Apart from hyperglycemia, other risk factors (notably high blood pressure, dyslipidemia, and obesity) are also very prevalent in diabetic patients.

Micro- and macroangiopathy exist side by side and their harmful effects are multiplied in DM2. Damage to the endothelium produced by accumulation of glucosilation sub-products, reduced production of nitric oxide, and endothelial inflammation are among the most characteristic mechanisms involved in the process.

\section{SOME EPIDEMIOLOGICAL DATA}

Over the last 50 years, people have experienced drastic changes in their environment, behavior, and lifestyles. 

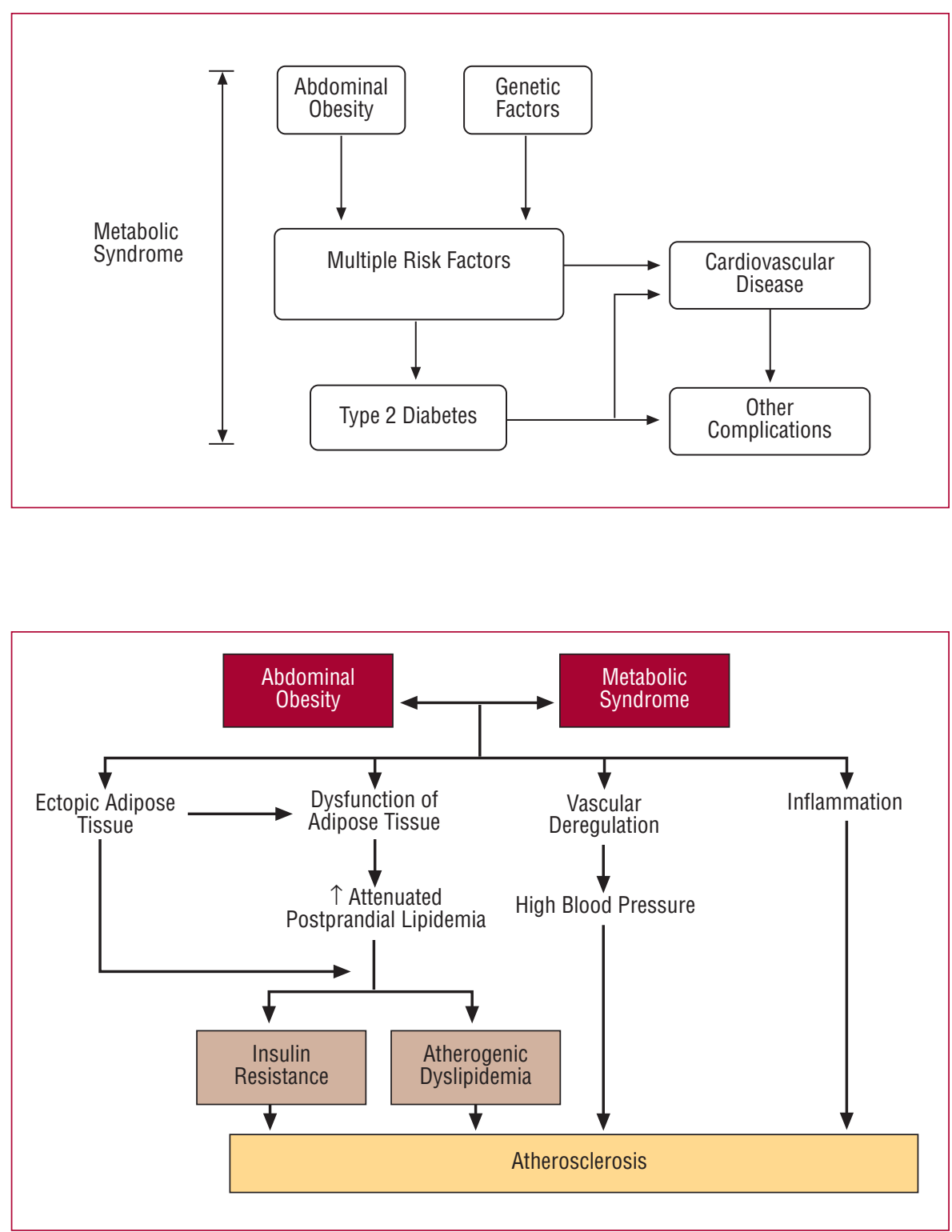

Figure 3. Evolution and pathology of the metabolic syndrome (adapted from Haslam et $\left.\mathrm{al}^{16}\right)$.

Figure 4. Metabolic syndrome as a dysfunction of adipose tissue (adapted from Laclaustra et $\mathrm{al}^{17}$ ).
These changes have led to the alarming increase in incidence of diabetes and obesity. ${ }^{20}$ The substitution of manual labor by mechanized processes, increased consumption of "empty calories," the globalization of technology, and improvements in transport are some of the factors which have led to this pandemic. ${ }^{21}$ One of the most recent studies into the prevalence of overweight, which was carried out by the WHO and the International Obesity Task Force, found that the worldwide prevalence, after adjusting for ethnic differences, was 1700 million overweight individuals, of which 312 million were obese. ${ }^{15,20}$ The trend in the obesity figures means that it is now considered one of the greatest health threats in the developed world. Data from successive cohorts of the National Health and Nutrition Examination Survey $(\text { NHANES })^{22}$ show that the mean waist circumference of adults in the USA increased by $3.1 \mathrm{~cm}$ between the 1988-1994 and 1999-2000 surveys. After adjusting by age, the largest increases in waist circumference were observed in the youngest age group (20-29 years). Over the past 20 years, prevalence rates for obesity have tripled in developing countries which have adopted western lifestyles. These have shown the typical patterns of reduced physical activity and over consumption of high energydensity meals. The last survey into the prevalence of overweight in CVD by the European Society of Cardiology (Euro-Heart Survey) was carried out in 8547 patients with chronic ischemic heart disease and found a prevalence of overweight (BMI $>25$ ) of $83 \%$ and of obesity (BMI $>30)$ of $38 \%$. Overall, $55 \%$ of the sample had central obesity (waist circumference $>102 \mathrm{~cm}$ in men, $>88 \mathrm{~cm}$ in women) (unpublished data). 
A

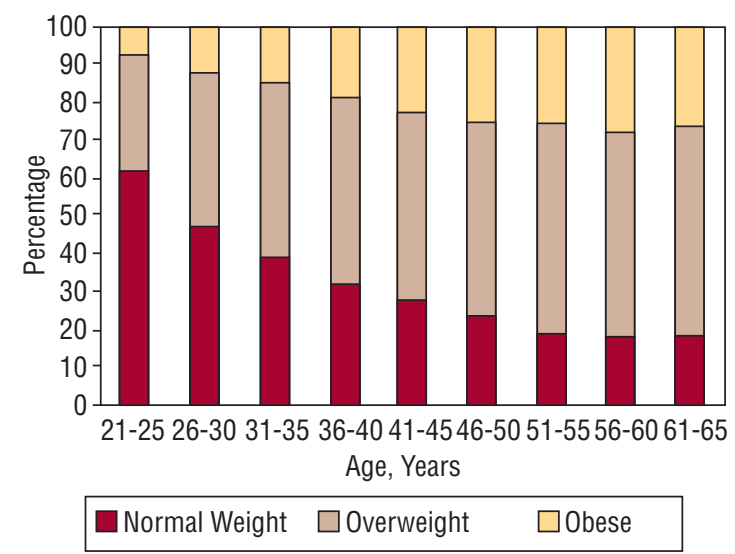

B

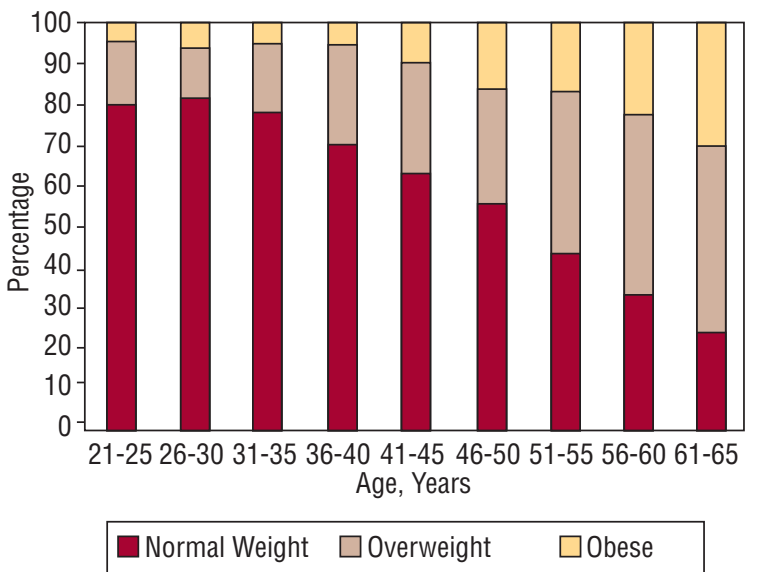

Figure 5. Prevalence of weight alterations in men (A) and women (B) in the MESYAS ${ }^{23}$ register of 18778 healthy men and women.

Figure 6. Prevalence of metabolic syndrome in the MESYAS ${ }^{23}$ register by age and gender in 18778 healthy members of the working population.

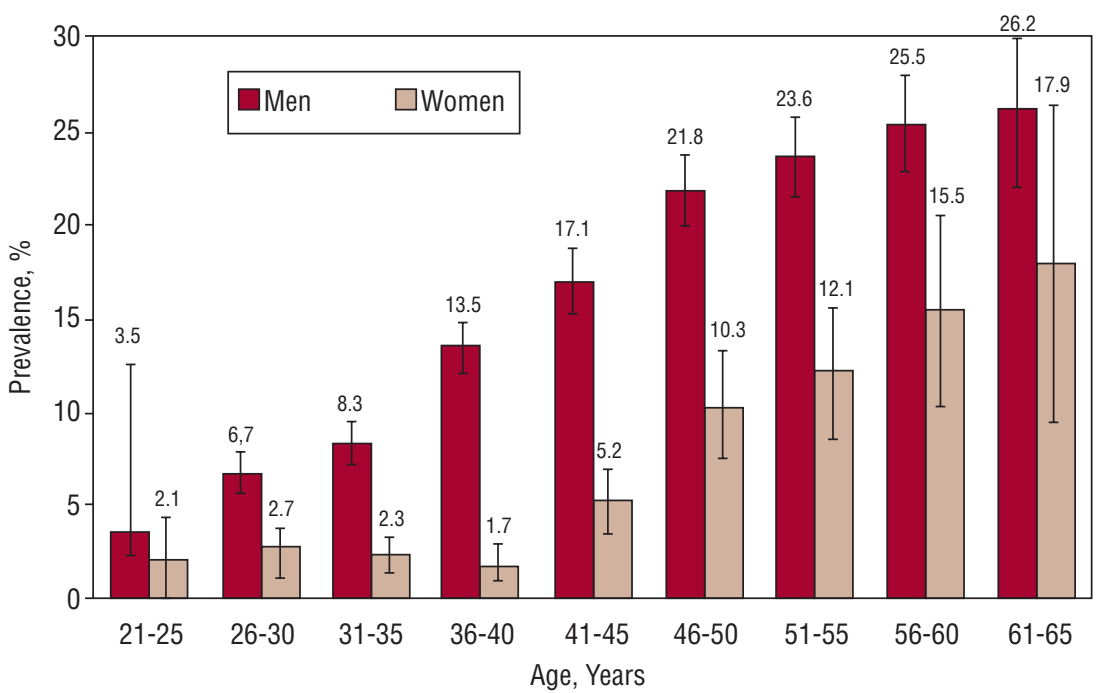

Finally, the DM2 epidemic is expanding principally in developed and developing countries. Estimates are not very encouraging and have taken public health authorities by surprise. Worldwide, the number of those with DM2 is expected to grow from the current 150 million to 220 million in 2010 and to 300 million in $2025 .^{24}$ The great majority will have DM2 associated with obesity and a sedentary lifestyle. This trend towards an increased prevalence of DM2 and obesity presents a real challenge for public health systems practically the whole world over and will continue to do so into the foreseeable future (Figure 7). 


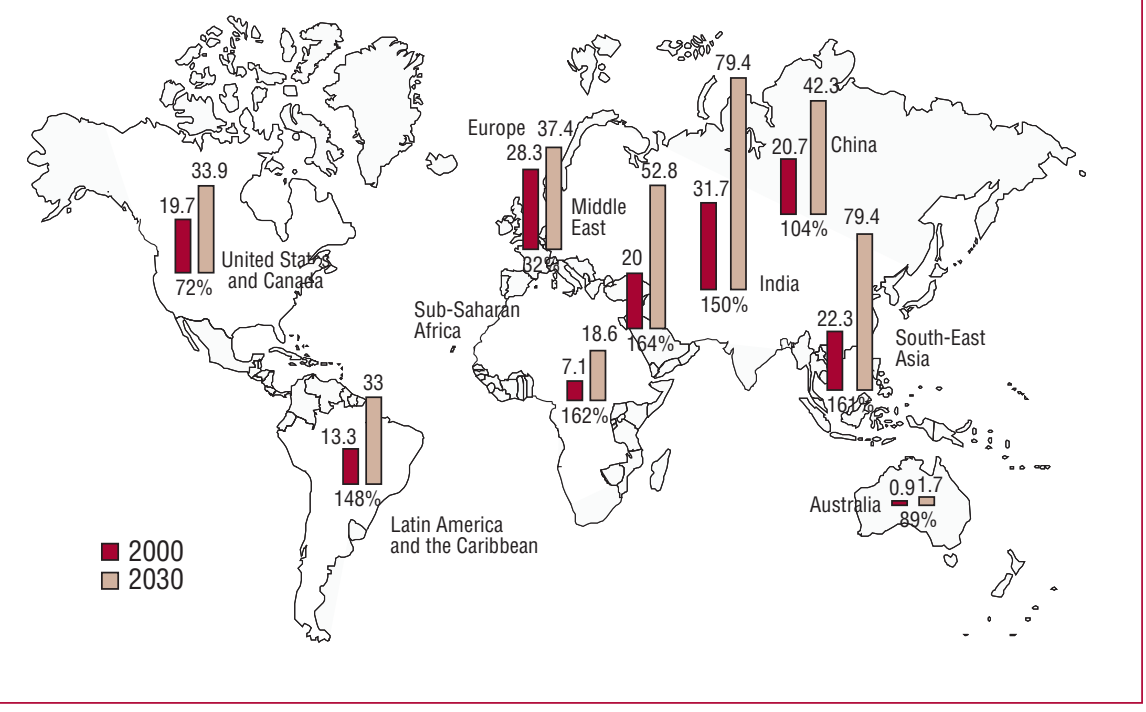

Figure 7. Diabetes cases (in millions of individuals) in 2000 and predicted for 2030.24

\section{DIAGNOSTIC APPROACH}

\section{Obesity and Metabolic Syndrome}

Diagnosis in individuals with obesity and MS should take into account the progressive nature of these conditions. In general, their evolution can be summarized in 4 phases, beginning with the presence of certain causal factors (central adiposity and insulin resistance, as well as genetic factors). These give rise to the metabolic alterations described above (high blood pressure, dyslipidemia, and glucose metabolism disorders) which in turn are followed by the development of vasculopathy. This is initially subclinical but eventually manifests as characteristic atherothrombotic complications and DM2 (Figure 3). Diagnosis should therefore not be limited to determining the presence of metabolic alterations, but should also explore the possibility of vasculopathic complications. ${ }^{13}$

Given the high risk associated with both diseases over the long term, it would seem logical to suggest that overall cardiovascular risk be assessed in all obese individuals or those with MS. Such an assessment should include checking on the presence and magnitude of MS components. Medium-term risk should be evaluated using risk prediction models adapted whenever possible to the local population, and the possibility of sub-clinical vasculopathy should be investigated using the appropriate procedures.

Signs of asymptomatic vasculopathy can be studied in all in vascular territories mostly affected by atherosclerosis (Table 4). ${ }^{25}$ If coronary heart disease is suspected, stress tests should be used to detect myocardial ischemia or alterations in perfusion together with non-invasive coronary angiographic imaging via multislice computed tomography or the classical technique. The possibility of an effect on cerebral blood flow can be studied by determining the intima media thickness of the common carotid artery, while the impact on peripheral circulation is measured most precisely using abdominal ultrasound to determine the diameter of the aorta. The ankle-brachial index can also be used as a non-invasive method to detect peripheral vascular disease, which correlates with vascular risk. Other, more general signs of sub-clinical vasculopathy are microalbuminuria and erectile dysfunction. ${ }^{25}$

\section{Diabetes}

Diabetes is now considered a vascular disease even when it clinical complications are not present. This approach is clearly important from the treatment point of view, though it is more doubtful when it comes to diagnosis, and has led to disagreement with the European Society of Cardiology's clinical practice guidelines on diabetes and pre-diabetes which strongly recommend that tests to detect myocardial ischemia are performed on all patients with DM2. ${ }^{26}$

\section{TABLE 4. Study of Sub-Clinical Vasculopathy}

\begin{tabular}{ll}
\hline Territory & Test \\
\hline Coronary & Tests of ischemia \\
& Multislice computed tomography \\
& Coronary angiography \\
Encephalic & IMT carotid \\
Periphery & Abdominal ultrasound \\
General & Ankle/brachial index \\
& Albuminuria \\
& Erectile dysfunction \\
& Endothelial function \\
\hline
\end{tabular}

IMT indicates intima media thickness. 
TABLE 5. Overview of Treatment for Metabolic Syndrome, Obesity, and Diabetes

\begin{tabular}{lll}
\hline Aspect & Treatment & Components \\
\hline Essential & Lifestyle & Diet \\
Complementary & Vascular protectors drugs & Aerobic exercise \\
& & Hypotensive drugs \\
& Lipid regulators \\
& Blood glucose \\
& & regulators \\
& & Anti-thrombotics \\
& Adjunctive drugs & Weight regulating \\
& & drugs \\
& Anti-ischemic drugs & Calcium antagonists \\
& & Nitrates \\
& & Others \\
& Revascularization & Percutaneous \\
& & Surgical \\
\hline
\end{tabular}

\section{PREVENTIVE TREATMENT}

Table 5 provides a summary of the general approach to treating the metabolic syndromes. ${ }^{13,27,28}$ The primary objective is to prevent onset of CVD, ${ }^{29,30}$ though it is equally important to delay or avoid onset of DM2 if it is not already present. ${ }^{13}$

\section{Life-Style}

Lifestyle is key to the treatment of DM2, MS, and obesity. ${ }^{13,26}$ If all of these conditions are due to the expression of a particular genetic predisposition exacerbated by an inappropriate lifestyle, then the first step in treatment is to modify that lifestyle. The three basic components in any such improvement are diet, exercise, and behavior.

The first essential step is weight loss (Figure 5). This apparently simple step (which is in fact the most difficult to achieve and, therefore, the least frequently achieved) has demonstrated numerous beneficial effects: it reduces mortality, improves lipid profiles, reduces blood pressure and left ventricle mass in hypertension, and it reduces inflammation markers in DM2. Furthermore, in patients with MS it has been shown that it slows progression to DM2. ${ }^{31}$ The same beneficial effects have also been observed in obese patients. ${ }^{32}$

As well as the quantitative aspect of a reduction in caloric uptake, dietary composition can also affect vascular health. Avoiding fats other than those from olive oil, increasing the consumption of fruits, vegetables, and whole-food cereals, avoiding industrially sweetened products and fatty meats, and eating white and especially blue fish are some of the recommendations in this regard (Table 6). ${ }^{33}$

Exercise has similar beneficial effects in MS, obesity, and DM2. As well as helping to achieve and maintain

\section{TABLE 6. Dietary Components and Vascular Risk}

\begin{tabular}{ll}
\hline Harmful & Protective \\
\hline Excess calories & $\begin{array}{c}\text { Mediterranean diet (fish, } \\
\text { vegetables and fruit, olive oil, } \\
\text { wine) } \\
\text { Vegetable steroles }\end{array}$ \\
$\begin{array}{l}\text { Saturated fats } \\
\text { Salt }\end{array}$ \\
$\begin{array}{l}\text { Refined carbohydrates } \\
\text { Alcohol (in excess) }\end{array}$ \\
\hline
\end{tabular}

weight loss, it also reduces all of the components of MS and reduces the incidence of CVD. ${ }^{34}$

It may be stating the obvious to insist that patients should be encouraged to give up smoking, but it is not enough only to offer advice; health care professionals should ensure they provide the requisite support for stopping smoking at all levels of cardiovascular risk.

\section{Treatment of High Blood Pressure}

According to the ADA and ESH/ESC guidelines, ${ }^{35}$ blood pressure targets in diabetes mellitus should be $<130 / 80 \mathrm{~mm} \mathrm{Hg}$. The same values are recommended for patients with MS. ${ }^{13}$

Angiotensin converting enzyme (ACE) inhibitors have demonstrated multiple beneficial effects on cardiovascular complications and for that reason are considered the first line, or preferred treatment for high blood pressure, particularly when established or incipient kidney disease is present. ${ }^{35,36}$ Some well-known studies have also shown that calcium antagonists are effective against CVD. ${ }^{37} \mathrm{In}$ DM2 patients, either of these treatments could be considered the most appropriate choice, alone or in combination. Beta-blockers are indicated where coronary artery disease or heart failure are present. Diuretics showed a satisfactory anti-hypertensive effect in some studies, ${ }^{38}$ though they also led to a worsened metabolic status ${ }^{39}$ and have no effect on arterial rigidity. For these reasons, beta-blockers and diuretics are considered complementary to ACE inhibitors and calcium channel blockers, with which they can be carefully used in combination to achieve appropriate levels of blood pressure control.

\section{Lipid-Lowering Treatment}

Lipid-lowering treatments are used based on the initial levels of lipids in blood with the aim of reaching targets set in international guidelines (Figure 8), ie LDL $<100$ $\mathrm{mg} / \mathrm{L}$, though a value of $<70 \mathrm{mg} / \mathrm{dL}$ may be selected if 


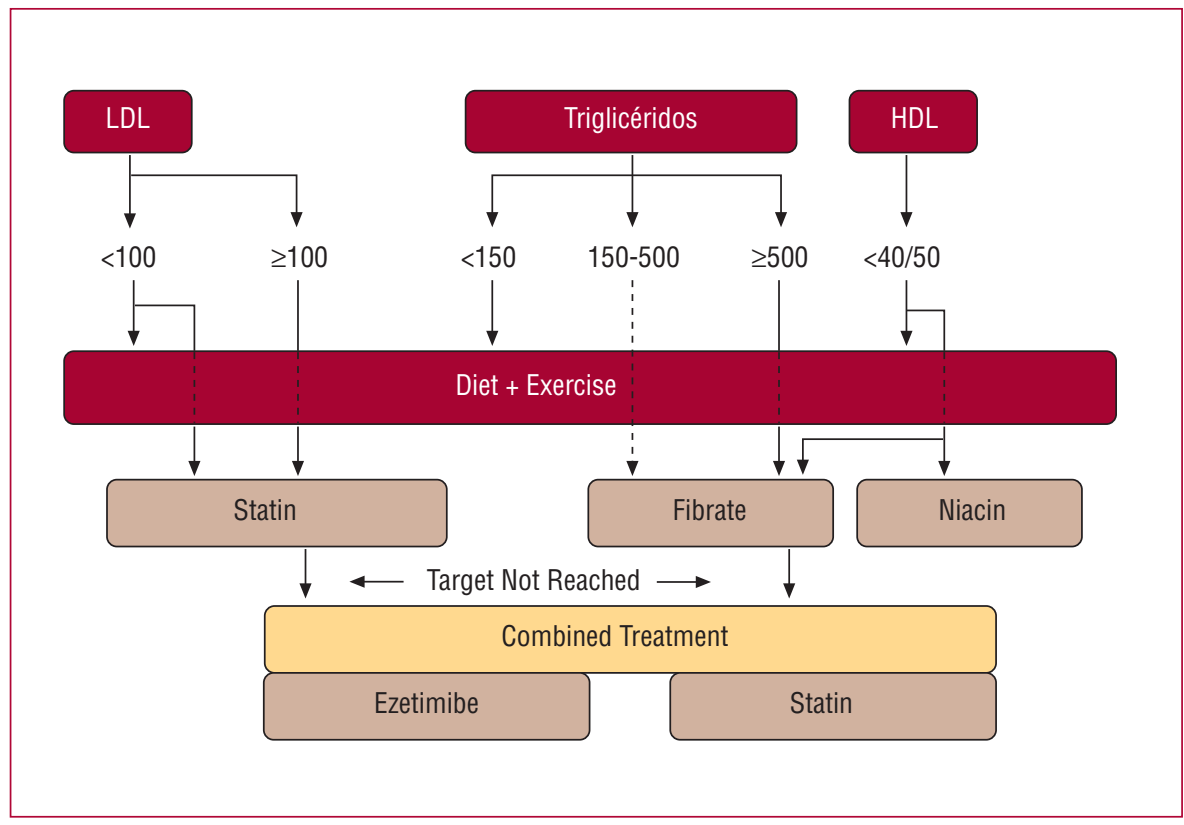

Figure 8. Diagram on the use of lipidlowering drugs in metabolic syndrome and type 2 diabetes (values in $\mathrm{mg} / \mathrm{dL}$ ). $\mathrm{HDL}$ indicates high density lipoproteins; LDL, low density lipoproteins.

cardiovascular risk is particularly high. A secondary, though very frequent and decisive objective in MS, obesity, and DM, is to lower cholesterol, other than HDL cholesterol, to levels $<130 \mathrm{mg} / \mathrm{dL}$ (optional $<100 \mathrm{mg} / \mathrm{dL}$ ). In order to prevent pancreatitis, triglycerides become a primary target for treatment when they exceed 500 $\mathrm{mg} / \mathrm{dL} .13,40$

Statins are the drug of choice to lower LDL levels. They have been shown to reduce serious cardiovascular complications by $21 \%$ and $23 \%$ in diabetic and nondiabetic patients, respectively, in both primary and secondary prevention. ${ }^{41}$ Statins are therefore essential treatment in patients with diabetes mellitus. The dose should be based on the size of the reduction required in LDL cholesterol. Any of the drugs in the group should be suitable; the important thing is to pursue and achieve the required dose and the targets set.

Fibrates are considered more effective than statins in lowering triglyceride and raising HDL levels, due to their agonist effect on PPAR $\alpha$. They might therefore appear to be an ideal treatment for atherogenic dyslipidemia in diabetes mellitus. ${ }^{42}$ However, the FIELD study showed that fenofibrate, one of the most widely used fibrates, did not significantly reduce the risk of coronary events. ${ }^{43}$ This has led to its usefulness as a preventive treatment being questioned. Nevertheless, fibrates are the primary indication in hypertriglyceridemia (target value $<150$ $\mathrm{mg} / \mathrm{dL}$ ).

The primary indication for niacin, which is not available in Spain, is to increase HDL concentrations, usually in combination with a statin. ${ }^{44}$ Fibrates can also be used to raise HDL cholesterol levels,${ }^{40}$ although extreme care should be taken if using them in combination with a statin (fenofibrate in this case) because of the possibility of myositis. This is particularly true in polymedicated patients or those who have renal dysfunction. ${ }^{45}$

\section{Antiplatelet Treatment}

Diabetes, MS, and even obesity are all prothrombotic conditions, with hyperaggregability and hypofibrinolysis. Acetylsalicylic acid has been shown to prevent atherothrombotic complications. ${ }^{46}$ The majority of clinical practice guidelines therefore recommend doses of 81$325 \mathrm{mg} /$ day, unless contraindicated, in all patients with diabetes and MS..$^{14,26}$

Figure 9 summarizes overall preventive treatment for cardiovascular and metabolic risk in patients with DM $2,{ }^{26}$ and which can be applied almost in their entirety to patients with MS. ${ }^{13}$

\section{SPECIFIC TREATMENTS}

\section{Hyperglycemia}

The aim of glucose regulating treatment is to reduce baseline blood glucose levels, glycohemoglobin $(<7 \%)$, and postprandial blood glucose levels. There is little data available on treatment strategies in patients with MS with respect to control of the carbohydrate mechanism. The most appropriate drugs in obesity and MS are acarbose, metformin, and the glitazones, administered alone or in combination depending on the circumstances. ${ }^{26}$

As regards DM2, the ADA/EASD treatment algorithm opts for strict control of glycohemoglobin using multiple treatments (Figure 10). ${ }^{47}$ Several studies have demonstrated that controlling glucose values can be an effective preventive measure. ${ }^{48}$ 
Figure 9. Overview of preventive treatment in patients with diabetes, ${ }^{26}$ also applicable in metabolic syndrome. ASA indicates acetylsalicylic acid; $C A$, calcium antagonist; ARA-II, angiotensin II receptor antagonist; $\mathrm{B} \beta$, beta-blockers; ED, erectile dysfunction; CVD, cardiovascular disease; IMTC, intimamedia thickness of carotid artery; HDL, high density lipoproteins; ACE, angiotensin converting enzyme; BMI, body mass index; $\mathrm{ABI}$, ankle/brachial index; LDL, low density lipoproteins; MAU, microalbuminuria; BP, blood pressure; MDCT, multi-detector computed tomography; TG, triglycerides.

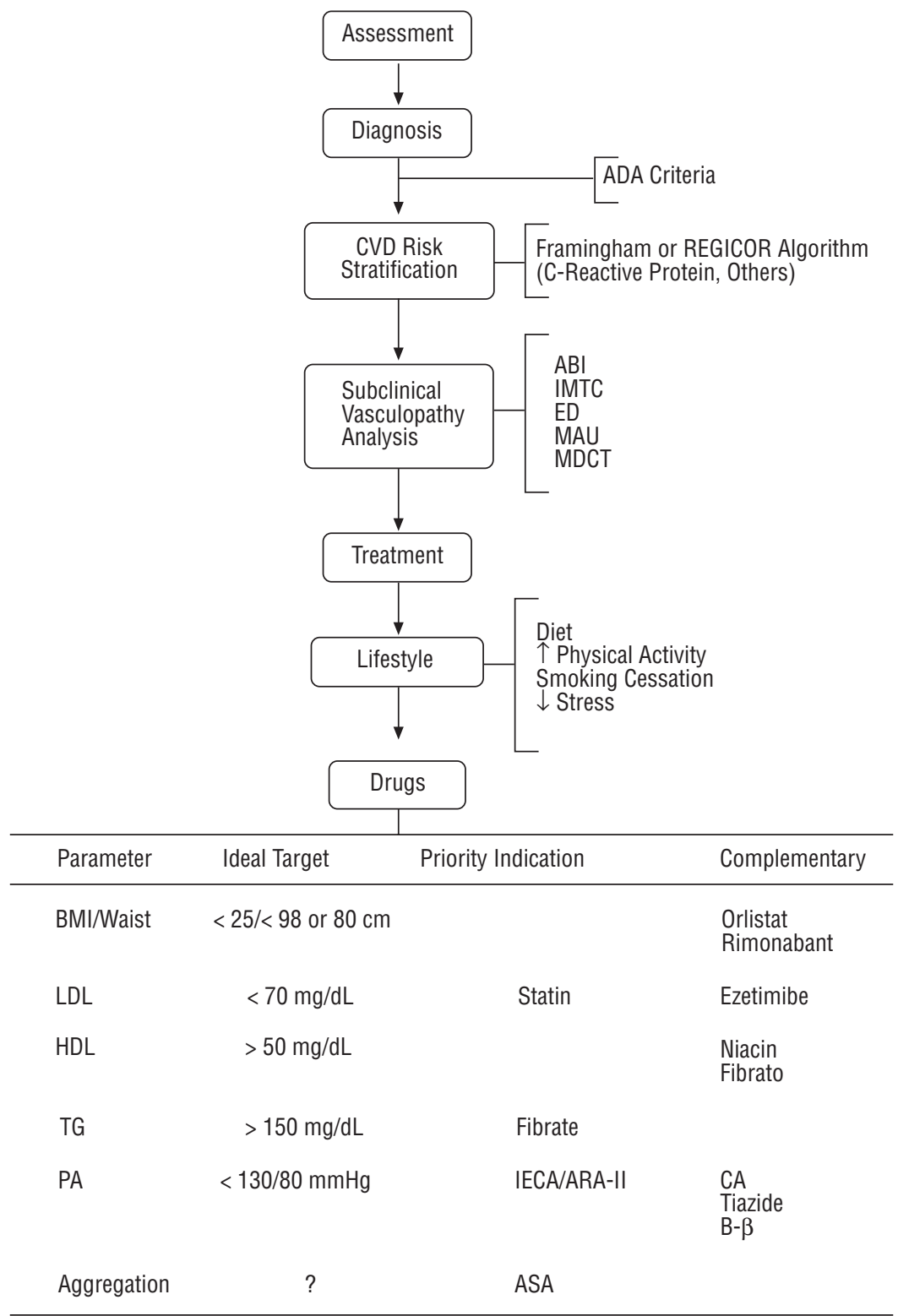

\section{Obesity}

Weight loss is associated with relevant reductions in CVD whether DM2 is present or not. ${ }^{49}$ The ideal objective is to reach a BMI of 25 (a more realistic value might be $<27$ ) or a waist circumference under that indicated as the threshold in the MS criteria. ${ }^{13}$ As well as diet and exercise, some drugs are useful for weight reduction. To date, only sibutramin and orlistat have been approved for use, though both have poor outcomes and are only moderately welltolerated. ${ }^{50}$
Rimonabant is a selective $\mathrm{CB} 1$ receptor blocker which has proven effective in achieving substantial weight loss and in reducing triglyceride levels and glycohemoglobin. It has also been shown to increase HDL cholesterol levels in obese patients and specifically in patients with diabetes.$^{51-53}$ Its possible psychological side effects require further study.

Bariatric surgery is indicated in morbidly obese patients or, in less advanced cases, when CVD or diabetes are also present. ${ }^{54}$ 


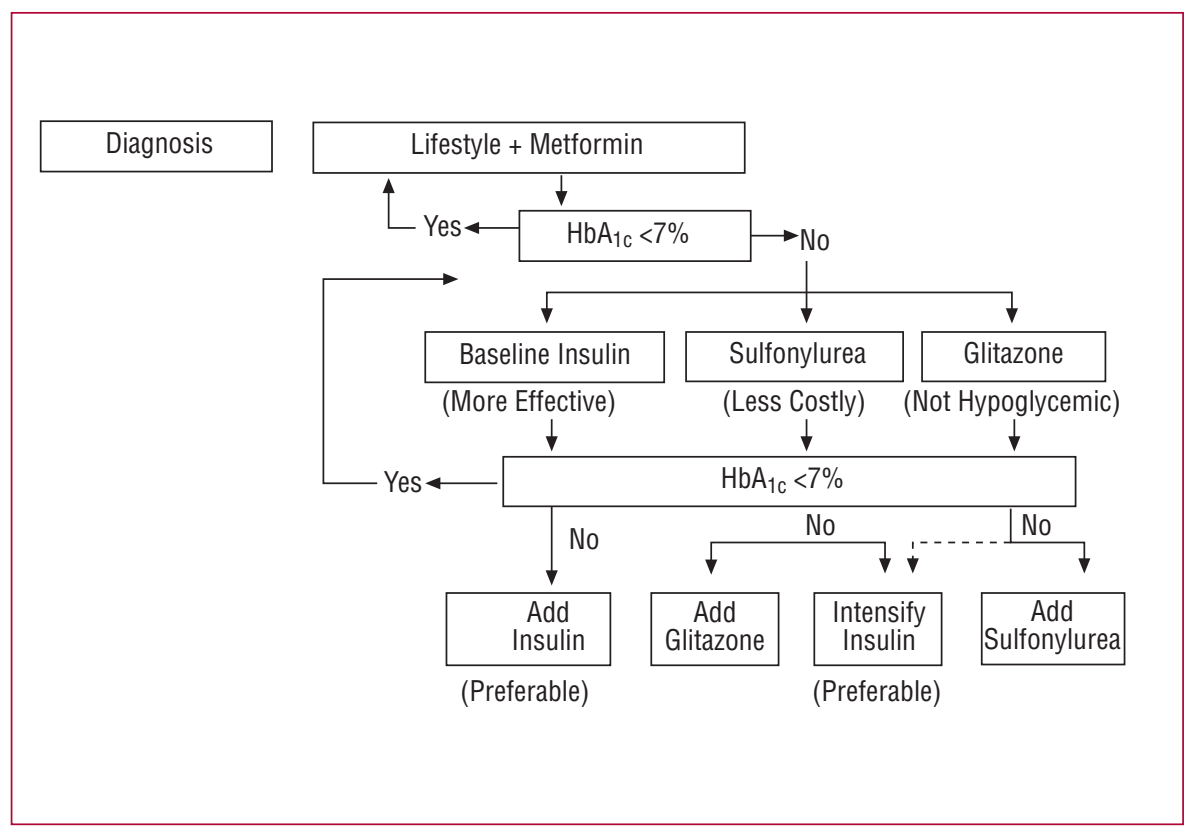

Figure 10. ADA/EASD algorithm for blood glucose control in type 2 diabetes (adapted from Nathan et $\mathrm{al}^{47}$ ). $\mathrm{HbA}_{1 \mathrm{c}}$, glycohemoglobin.

\section{Vascular Complications}

Peripheral vascular complications should be managed using percutaneous or surgical procedures corresponding to the condition in question.

As regards cardio-ischemic complications, treatment should be similar to that used in any other case of chronic angina. Antianginal drugs and revascularization will be used depending on level of functioning and coronary anatomy. The classic antianginal drugs (nitrates, beta blockers, and calcium antagonists) can all be used in patients with MS, obesity, or DM2. ${ }^{28}$

In acute coronary syndromes, strict glucose control using insulin perfusion is essential and has been shown to reduce the incidence of some adverse outcomes. ${ }^{55}$ In acute cases, the recommended values are as close as possible to $110 \mathrm{mg} / \mathrm{dL}$, and always $<180 \mathrm{mg} / \mathrm{dL} .{ }^{14} \mathrm{In}$ non-critical hospitalized patients, prandial insulin can be used, with control values ranging from 90 to $130 \mathrm{mg} / \mathrm{dL}$ (fasting) and $<180 \mathrm{mg} / \mathrm{dL}$ after meals. ${ }^{14}$

Criteria for revascularization in patients with DM2 are influenced by the greater risk (which requires the use of more intensive treatments) and lower success rates associated with revascularization procedures in these patients. ${ }^{56,57}$

\section{REFERENCES}

1. Barness LA, Opitz JM, Gilbert-Barness E. Obesity: genetic, molecular, and environmental aspects. Am J Med Genet. 2007; 143:3016-34.

2. Roche AF, Sievogel RM, Chumlea WC, Webb P. Grading body fatness from limited anthropometric data. Am J Clin Nutr. 1981;34:2831-8.
3. Flegal KM, Ogden CL, Wei R, Kuczmarscki RL, Johnson CL. Prevalence of overweight in US children: comparison of US growth charts from the Centers for Disease Control and Prevention with other reference values for body mass index. Am J Clin Nutr. 2001;73:1086-93.

4. National Institutes of Health. Clinical guidelines on the identification evaluation, and treatment of overweight and obesity in adults. The evidence report. Obes Res. 1998;6 Suppl 2:S51-209.

5. Allison DB, Heshka S. Toward an empirically derived typology of obese persons. Int J Obes. 1991;15:741-54.

6. Walton C, Lees B, Crook D, Worthington M, Goldsland IF, Stevenson JC. Body fat distribution, rather than overall adiposity, influences serum lipids and lipoproteins in healthy men independently of age. Am J Med. 1995;99:459-64.

7. Ruderman NB, Schneider SH, Berchtold P. The "metabolicallyobese," normal-weight individual. Am J Clin Nutr. 1981;34:1617-21.

8. Karelis AD, Faraj B, Bastard JP, St-Pierre DH, Brochu M, Prud'homme D, et al. The metabolically healthy but obese individual presents a favorable inflammation profile. J Clin Endocrinol Metab. 2005;90:4145-50.

9. Yusuf S, Hawken S, Ounpuu S, Bautista L, Franzosi MG, Commerford P, et al; INTERHEART Study Investigators. Obesity and the risk of myocardial infarction in 27,000 participants from 52 countries: a case-control study. Lancet. 2005;366:1640-9.

10. Reaven GM. The insulin resistance syndrome. Curr Atheroscler Rep. 2003;5:364-71.

11. Reilly MP, Rader DJ. The metabolic syndrome: more than the sum of its parts? Circulation. 2003;108:1546-51.

12. Alberti KG, Zimmet P, Shaw J, for the IDF Epidemiology Task Force Consensus Group. The metabolic syndrome: a new worldwide definition. Lancet. 2005;366:1059-72.

13. Grundy SM, Cleeman JI, Daniels SR, Donato KA, Eckel RH, Franklin $\mathrm{BA}$, et al. Diagnosis and management of the metabolic syndrome: An American Heart Association/National Heart, Lung, and Blood Institute scientific statement. Curr Opin Cardiol. 2006;21:1-6.

14. American Diabetes Association. Standards of medical care in diabetes2008. Diabetes Care. 2008;31 Suppl 1:S12-54.

15. Haslam DW, James WP. Obesity. Lancet. 2005;366:1197-209.

16. Grundy SM. Metabolic syndrome: connecting and reconciling cardiovascular and diabetes worlds. J Am Coll Cardiol. 2006;47: 1093-100. 
17. Laclaustra M, Corella D, Ordovas JM. Metabolic syndrome pathophysiology: the role of adipose tissue. Nutr Metab Cardiovasc Dis. 2007;17:129-39.

18. Lebovitz HE. Insulin resistance: a common link between type 2 diabetes and cardiovascular disease. Diabetes Obes Metab. 2006; $8: 237-49$.

19. Thomas JE, Foody JM. The pathophysiology of cardiovascular disease in diabetes mellitus and the future of therapy. J Cardiometab Syndr. 2007;2:108-13.

20. Hassain P, Kawar B, El Nahas M. Obesity and diabetes in the developing world: a growing challenge. N Engl Med. 2007; 352:213-6.

21. Zimmet P. Globalization, coca-colonization and the chronic disease epidemic: can the doomsday scenario be averted? J Intern Med. 2000;247:301-10.

22. Alexander CM, Landsman PB, Teutsch SM, Haffner SM, for the Third National Health and Nutrition Examination Survey (NHANES III); National Cholesterol Education Program (NCEP). NECPdefined metabolic syndrome, diabetes, and prevalence of coronary heart disease among NHANES III participants aged 50 years and older. Diabetes. 2003;52:1210-4.

23. Alegría E, Cordero A, Laclaustra M, Grima A, León M, Casasnovas JA, et al; Investigadores del registro MESYAS. Prevalencia de síndrome metabólico en población laboral española: Registro MESYAS. Rev Esp Cardiol. 2005;58:797-806.

24. Zimmet P, Alberti KG, Shaw S. Global and societal implications of diabetes epidemic. Nature. 2001;414:782-7.

25. Cairols M, Castillo J, González-Juanatey JR, Mostaza JM, Pomar JL. Enfermedad arterial asintomática. Rev Clin Esp. 2003;203 Suppl 3:1-57.

26. Rydén L, Standl E, Bartnik M, van den Berghe G, Betteridge J, de Boer M-J, et al. Guías de práctica clínica sobre diabetes, prediabetes y enfermedades cardiovasculares. Rev Esp Cardiol. 2007;60 525.e1-e64.

27. Heinig RE. The patient with diabetes: preventing cardiovascular complications. Clin Cardiol. 2006;29 Suppl 10:II13-20.

28. Srikanth S, Deedwania P. Management of coronary artery disease in patients with type 2 diabetes mellitus. Curr Cardiol Rep. 2007;9:264-71.

29. Hobbs FDR. Reducing cardiovascular risk in diabetes: Beyond glycemic and blood pressure control. Int J Cardiol. 2006;110: 137-45.

30. Buse JB, Ginsberg HN, Bakris GL, Clark NG, Costa F, Eckel R, et al. Primary prevention of cardiovascular diseases in people with diabetes mellitus: a scientific statement from the American Heart Association and the American Diabetes Association. Circulation. 2007;115:114-26.

31. Toumilehto J, Lindström J, Eriksson JG, Valle TT, Hämäläinen H, Ilanne-Parikka P, et al; Finnish Diabetes Prevention Study Group. Prevention of type 2 diabetes mellitus by changes in lifestyle among subjects with impaired glucose tolerance. N Engl J Med. 2001; 344:1343-50.

32. Poirier P, Giles TD, Bray GA, Hong Y, Stern JS, Pi-Sunyer FX, et al. Obesity and cardiovascular disease: pathophysiology, evaluation, and effect of weight loss. An Update of the 1997 American Heart Association Scientific Statement on Obesity and Heart Disease From the Obesity Committee of the Council on Nutrition, Physical Activity, and Metabolism. Circulation. 2006;113:898-918.

33. Serra L, Roman B, Estruch R. Scientific evidence of interventions using the Mediterranean diet: a systematic review. Nutr Rev. 2006;64 Suppl 2:S27-47.

34. Warburton DER, Nicol CW, Bredin SSD. Health benefits of physical activity: the evidence. CMAJ. 2006;174:801-9.

35. Mancia G, de Backer G, Dominiczak A, Cifkova R, Fagard R, Germano G, et al. Guías de práctica clínica para el tratamiento de la hipertensión arterial 2007. Rev Esp Cardiol. 2007;60:968.e1-e94.

36. González-Juanatey JR, Mazón P, Soria F, Barrios V, Rodríguez L, Bertomeu V. Actualización (2003) de las Guías de Práctica Clínica de la Sociedad Española de Cardiología en hipertensión arterial. Rev Esp Cardiol. 2003;56:487-97.
37. Dahlöf B, Sever PS, Poulter NR, Wedel H, Beevers DG, Caulfield $\mathrm{M}$, et al, for the ASCOT Investigators. Prevention of cardiovascular events with an antihypertensive regimen of amlodipine adding perindopril as required versus atenolol adding bendroflumethiazide as required, in the Anglo-Scandinavian Cardiac Outcomes TrialBlood Pressure Lowering Arm (ASCOT-BPLA): a multicentre randomised controlled trial. Lancet. 2005;366:895-906.

38. Whelton PK, Barzilay J, Cushman WC, Davis BR, Iiamathi E, Kostis $\mathrm{JB}$, et al, for the ALLHAT Collaborative Research Group. Clinical outcomes in antihypertensive treatment of type 2 diabetes, impaired fasting glucose concentration, and normoglycemia: Antihypertensive and Lipid-Lowering Treatment to Prevent Heart Attack Trial (ALLHAT). Arch Intern Med. 2005;165:1401-9.

39. Elliott WJ, Meyer PM. Incident diabetes in clinical trials of antihypertensive drugs: a network meta-analysis. Lancet. 2007;369: 201-7.

40. Grundy SM, Cleeman JI, Merz CN, Brewer JB, Clark LT, Hunninghake DB, et al, for the Coordinating Committee of the National Cholesterol Education Program. Implications of recent clinical trials for the National Cholesterol Education Program Adult Treatment Panel III Guidelines. J Am Coll Cardiol. 2004;44: 720-32.

41. Costa J, Borges M, David C, Vaz A. Efficacy of lipid lowering drug treatment for diabetic and non-diabetic patients: metaanalysis of randomised controlled trials. BMJ. 2006;332:1115-24.

42. Tsimihodimos V, Miltiadous G, Daskalopoulou SS, Mikhailidis DP, Elisaf MS. Fenofibrate: metabolic and pleiotropic effects. Curr Vasc Pharmacol. 2005;3:87-98

43. Keech A, Simes RJ, Barter P, Best J, Scott R, Taskinen MR, et al, for the FIELD Study Investigators. Effects of long-term fenofibrate therapy on cardiovascular events in 9795 people with type 2 diabetes mellitus (the FIELD study): randomised controlled trial. Lancet. 2005;366:1849-61.

44. Shepherd J, Betteridge J, van Gaal L, for the European Consensus Panel. Nicotinic acid in the management of dyslipidaemia associated with diabetes and metabolic syndrome: a position paper developed by a European Consensus Panel. Curr Med Res Opin. 2005;21: 665-82.

45. Davidson MH. Statin/fibrate combination in patients with metabolic syndrome or diabetes: evaluating the risks of pharmacokinetic drug interactions. Expert Opin Drug Saf. 2006;5:145-56.

46. Antithrombotic Trialists' Collaboration. Collaborative metaanalysis of randomised trials of antiplatelet therapy for prevention of death, myocardial infarction, and stroke in high risk patients. BMJ. 2002; 324:71-86.

47. Nathan DM, Buse JB, Davidson MB, Ferrannini E, Holman RR, Sherwin R, et al. Management of hyperglycemia in type 2 diabetes: A consensus algorithm for the initiation and adjustment of therapy. Update regarding thiazolidinediones: a consensus statement from the American Diabetes Association and the European Association for the Study of Diabetes. Diabetes Care. 2008;31:173-5.

48. Anselmino M, Ohrvik J, Malmberg K, Standl E, Rydén L. Glucose lowering treatment in patients with coronary artery disease is prognostically important not only in established but also in newly detected diabetes mellitus: a report from the EuroHeart Survey on Diabetes and the Heart. Eur Heart J. 2008;29:177-84.

49. Sharma AM. The obese patient with diabetes mellitus: from research targets to treatment options. Am J Med. 2006;119 Suppl 5A: S17-23.

50. Ioannidis-Demos LL, Proietto J, McNeil JJ. Pharmacotherapy for obesity. Drugs. 2005;65:1391-418.

50. van Gaal LF, Rissanen AM, Scheen AJ, Ziegler O, Rossner S. Effects of the cannabinoid-1 receptor blocker rimonabant on weight reduction and cardiovascular risk factors in overweight reduction and cardiovascular risk factors in overweight patients: 1-year experience form the RIO-Europe study. Lancet. 2005;365:1389-97.

51. Scheen AJ, Finer N, Hollander P, Jensen MD, van Gaal LF; RIODiabetes Study Group. Efficacy and tolerability of rimonabant in 
overweight or obese patient with type 2 diabetes: a randomised controlled study. Lancet. 2006;368:1660-72.

52. Christensen R, Kristensen PK, Bartels EM, Bliddal H, Astrup A. Efficacy and safety of the weight-loss drug rimonabant: a metaanalysis of randomised trials. Lancet. 2007;370:1706-13.

53. Levy P, Fried M, Santini F, Fines N. The comparative effects of bariatric surgery on weight and type 2 diabetes. Obes Surg. 2007; 17:1248-56.

54. Malmberg K, Rydén L, Wedel H, Birkeland K, Bootsma A, Dickstein $\mathrm{K}$, et al; DIGAMI 2 Investigators. Intense metabolic control by means of insulin in patients with diabetes mellitus and acute myocardial infarction (DIGAMI 2): effects on mortality and morbidity. Eur Heart J. 2005;26:650-61.

55. Stone KE, Chiquette E, Chilton RJ. Diabetic endovascular disease: role of coronary artery revscularization. Am J Cardiol. 2007;99 Suppl 4A:B105-12.

56. Bravata DM, Gienger AL, McDonald KM, Sundaram V, Perez MV, Varghese R, et al. Systematic review: the comparative effectiveness of percutaneous coronary interventions and coronary artery bypass graft surgery. Ann Intern Med. 2007;147:703-16. 